\title{
DOCUMENTING BRONZE AGE AKROTIRI ON THERA USING LASER SCANNING, IMAGE-BASED MODELLING AND GEOPHYSICAL PROSPECTION
}

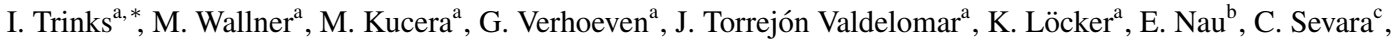 \\ L. Aldrian ${ }^{\mathrm{a}}$, W. Neubauer ${ }^{\mathrm{a}, \mathrm{c}}$, M. Klein ${ }^{\mathrm{d}}$ \\ ${ }^{\text {a }}$ Ludwig Boltzmann Institute for Archaeological Prospection and Virtual Archaeology, Hohe Warte 38, 1190 Vienna, Austria - \\ (immo.trinks, mario.wallner, matthias.kucera, geert.verhoeven, juan.torrejon-valdelomar, klaus.loecker, lisa.aldrian, \\ wolfgang.neubauer)@archpro.lbg.ac.at \\ ${ }^{\mathrm{b}}$ Norwegian Institute for Cultural Heritage Research, Postboks 736, Sentrum, N-0105 Oslo, Norway - erich.nau@ niku.no \\ ${ }^{c}$ Vienna Institute for Archaeological Science, Franz-Klein-Gasse 1, 1190 Vienna, Austria - \\ (wolfgang.neubauer, christopher.sevara)@univie.ac.at \\ d 7reasons Medien GmbH, Bäuerlegasse 4-6, 1200 Vienna, Austria - mk@7reasons.net
}

\section{Commission II}

KEY WORDS: cultural heritage documentation, laser scanning, image-based modelling, ground-penetrating radar, virtual reconstruction

\begin{abstract}
:
The excavated architecture of the exceptional prehistoric site of Akrotiri on the Greek island of Thera/Santorini is endangered by gradual decay, damage due to accidents, and seismic shocks, being located on an active volcano in an earthquake-prone area. Therefore, in 2013 and 2014 a digital documentation project has been conducted with support of the National Geographic Society in order to generate a detailed digital model of Akrotiri's architecture using terrestrial laser scanning and image-based modeling. Additionally, non-invasive geophysical prospection has been tested in order to investigate its potential to explore and map yet buried archaeological remains. This article describes the project and the generated results.
\end{abstract}

\section{INTRODUCTION}

\subsection{The archaeological site of Akrotiri on Thera/Santorini}

The Bronze Age settlement of Akrotiri on the Greek island Thera/ Santorini in the southern Aegean Sea was prior to the catastrophic Minoan Thera eruption, in approximately 1613 BCE (Friedrich, 2009; Heinemeier et al., 2009), home to an affluent society (Palyvou, 2005). Several of the multi-storey buildings had been richly decorated with naturalistic frescoes that provide fascinating insights into the culture of this technologically advanced civilisation, that over 3,600 years ago already possessed advanced sewerage systems and far reaching contacts, as illustrated for instance by exotic animals depicted in the wall paintings.

The first archaeological excavations in the area of Akrotiri were conducted by French archaeologist Henri Mamet and geologist Henri Gorceix in 1870, resulting in the discovery of Bronze Age architecture (Fouqué, 1879; Tzachili, 2005; Friedrich, 2009). In 1899 the German archaeologist Robert Zahn worked on behalf of archaeologist Friedrich Hiller von Gaertringen in the area of the Potamos ravine south-easterly of the village of Akrotiri. Here remains of prehistoric buildings, ceramics and household objects were found underneath thick layers of pumice deposited by the Minoan volcanic eruption. The exact location of Zahn's excavation had been unknown in modern times (Mavor, 1973; Castleden, 1998). Archaeological excavations conducted since 1967 by Spyridon Marinatos (1999 a,b,c) and since 1974 by Christos Doumas (1983) along a ravine cutting through the volcanic pumice deposited south of the village of Akrotiri have revealed exceptional remains of a Bronze Age settlement, providing unique insights into the life and culture of its residents (Marinatos, 1984).

\footnotetext{
${ }^{*}$ Corresponding author
}

\subsection{Objective of the project}

The motivation for this digital documentation and archaeological prospection project is the situation that the excavated architecture of Bronze Age Akrotiri is endangered, being located on an active volcano in one of the world's seismically most active regions. In the past years, and particularly since winter 2010, at the comparable Italian site of Pompeii, considerable damage has been caused to ancient architecture, with entire buildings (The House of Gladiators, Nov. 2010) and several walls having collapsed after heavy rainfall, dramatically illustrating the risks of losing valuable cultural heritage that had been exposed by excavation. Pompeii, covering some 60 hectares of area, is much larger than the excavated site of Akrotiri (covering circa 1.2 ha).

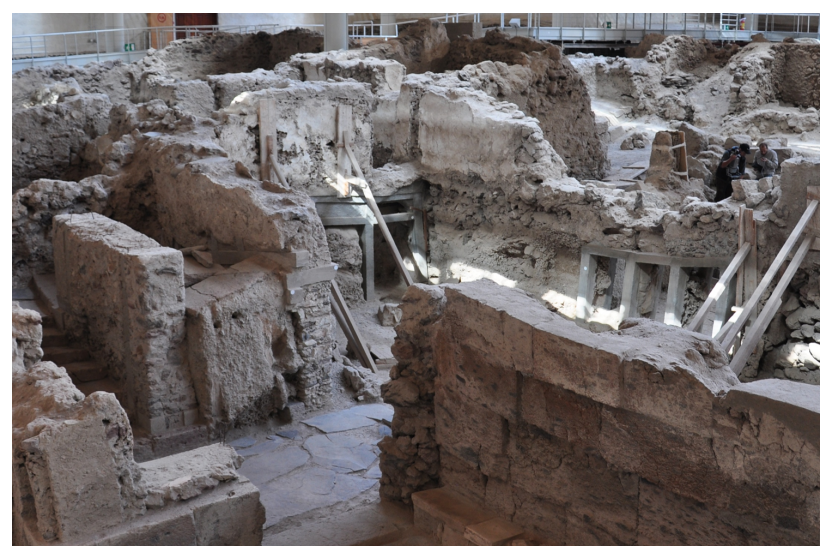

Figure 1: Excavated walls of the building Xeste 3 at Akrotiri just propped up with wooden beams, vulnerable to destruction in the case of earthquakes. 


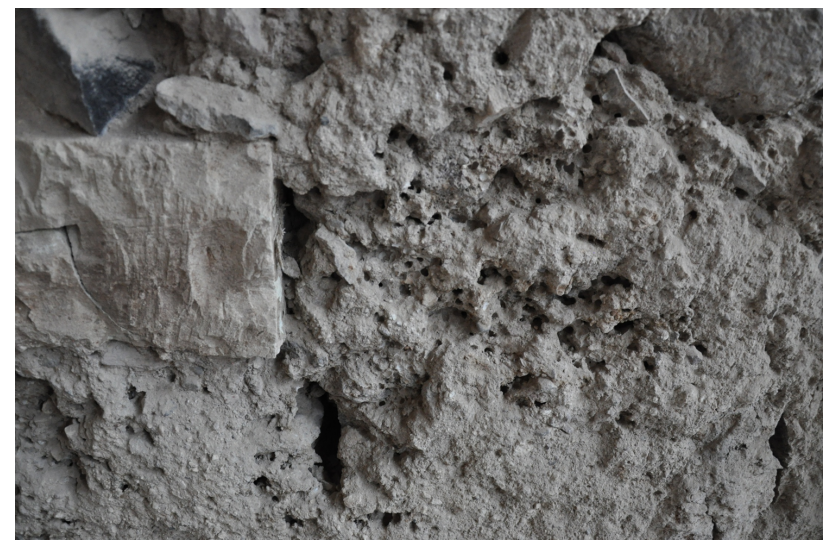

Figure 2: Holes dug into a prehistoric wall at Akrotiri by mud dauber wasps in search of clay, undermining the wall's stability.

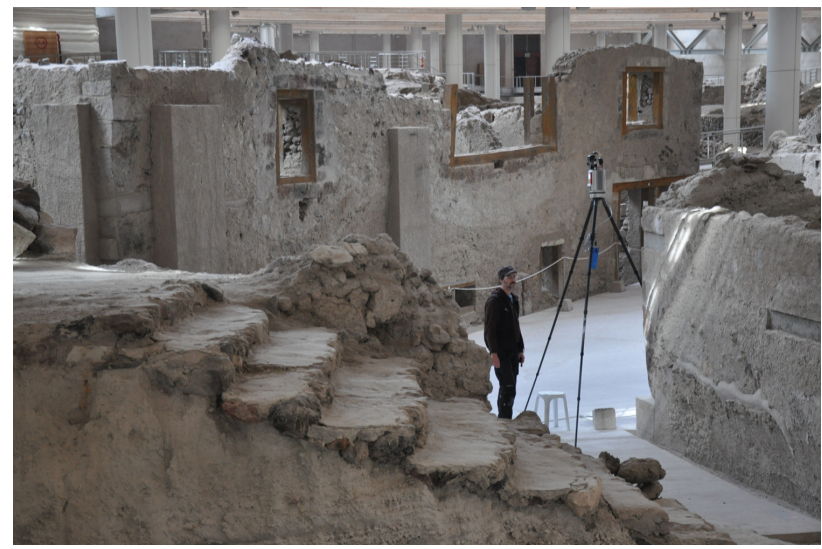

Figure 3: Laser scanning with a Riegl VZ-400 scanner in front of Westhouse on Triangle square of Akrotiri.

Furthermore, Akrotiri has been protected with a shelter, shielding the excavated architecture against the weather. However, at Akrotiri the risk of likely future earthquakes looms, with many of the multi-storey structures only propped up with fragile wooden beams (Fig. 1). Additionally, gradual decay as well as accidents endanger the excavated architecture, as the partial collapse of the protective roof in 2005 unfortunately demonstrated. Mason wasps searching for clay undermine the fabric of the prehistoric walls (Fig. 2). Broken glass stripes that had been attached over cracks in walls for monitoring purposes are witness to gradual decay. Therefore the project, which has partially been funded by a grant provided by the National Geographic Society, was meant to generate a high-resolution digital model of excavated architecture by terrestrial laser scanning (TLS) and image-based modelling (IBM) for the virtual safeguarding of this unique archaeological heritage.

In addition to the digital documentation of the excavated site of Akrotiri, the project attempted to test non-invasive groundpenetrating radar (GPR) and earth resistance tomography for the detection and mapping of buried prehistoric remains. The first GPR tests, conducted by Greek pioneer Gregory Tsokas in 1996, had been hampered by the strong absorption of the electromagnetic GPR signal by the topmost layer of pumice. Since excavations expose the uncovered prehistoric architecture to the potential risk of destruction, it was thought that non-invasive geophysical prospection methods may harbour a potential at Akrotiri to discover and map yet buried Bronze Age architecture.

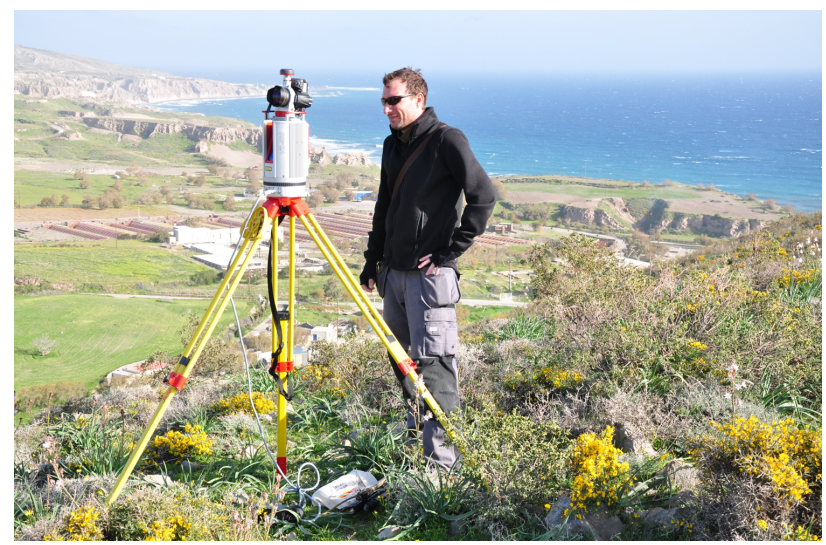

Figure 4: Outdoor laser scanning with the Riegl VZ-400 scanner on Mesa Vouno ridge west of the Akrotiri excavation site, whose shelter is visible in the background.

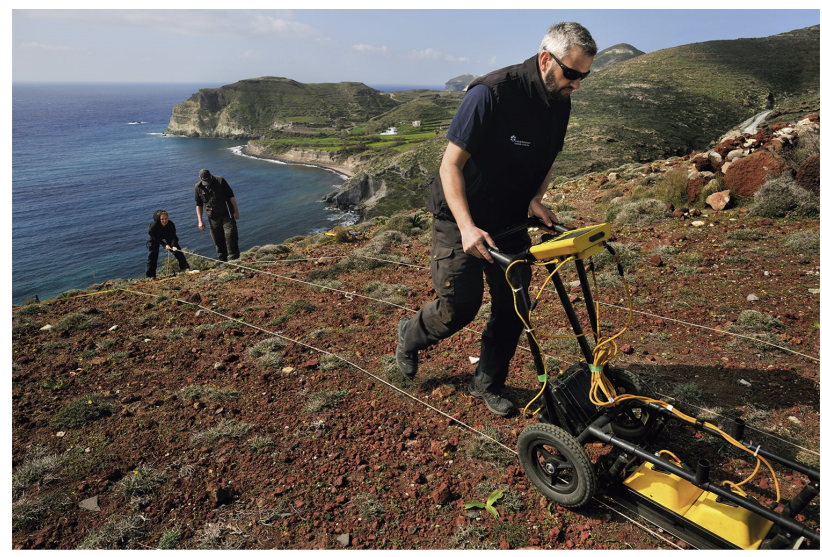

Figure 5: Ground-penetrating radar measurements on top of Kokkino Vouno, one of the few sites on Thera where the preeruption surface is exposed.

\section{METHODS}

\subsection{Data acquisition}

In February 2013, the excavated site of Akrotiri was digitally documented using two Riegl VZ-400 laser scanners (Fig. 3), featuring a measurement accuracy of $5 \mathrm{~mm}$ and a $1 \sigma$ precision of $3 \mathrm{~mm}$ at $100 \mathrm{~m}$ range under Riegl test conditions, with top-mounted Nikon D700 reflex cameras. A total of 817 scan positions were recorded, amounting to some 8 billion data points, and an average point density of 2 points $/ \mathrm{cm}^{2}$. All scan stations were georeferenced using a multitude of flat and cylindrical targets surveyed by total station.

In addition to TLS, a passive, image-based method for the geometrical 3D documentation of various parts of the interior of the excavated site of Akrotiri has been applied. In an initial phase, the entire site was photographed from the pathways leading through the excavation. Afterwards, the so-called House of the Ladies and the building Complex Beta (Fig. 8) were photographically documented as well. All conventional, three-band colour imagery was acquired using a Nikon D7000, a 16 megapixel APS-C format reflex camera. The Nikon body was fitted with a Tokina 11$16 \mathrm{~mm} f / 2.8$ AT-X Pro DX lens, whose focal length was fixed at either $11 \mathrm{~mm}, 12 \mathrm{~mm}$ or $13 \mathrm{~mm}$ while the focus was fixed at circa $3 \mathrm{~m}$. The D7000 was always set to capture RAW imagery. Given 


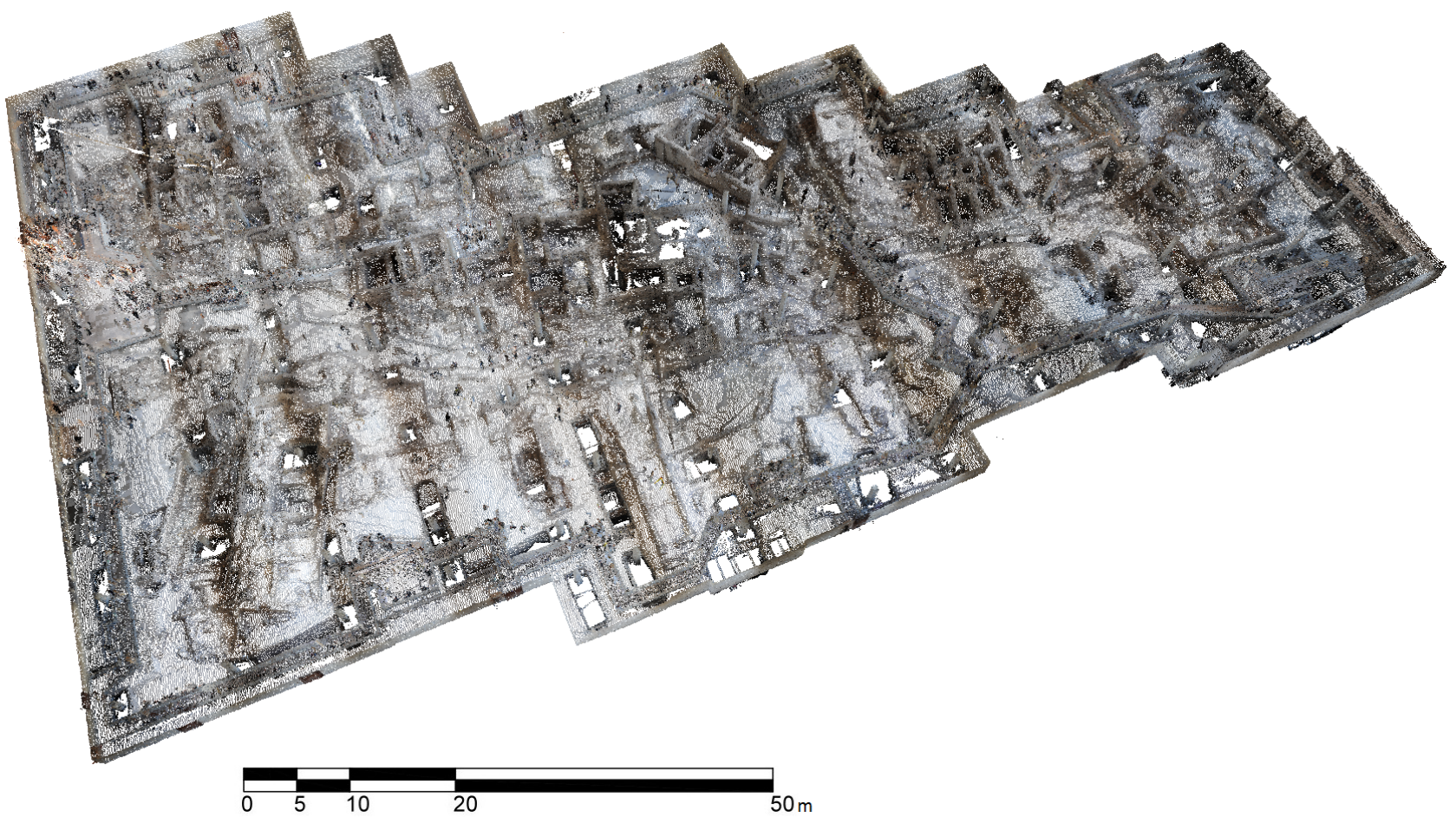

Figure 6: Overview of the reduced laser scanning data acquired across the entire excavated site of Akrotiri. Holes in the data equal the areas where modern pillars were erected to support the protective shelter. In the centre, in Complex Delta the roof had collapsed in 2005. Therefore, two rooms could not be accessed there, as well as one room in Westhouse.

these predefined focal lengths and focus settings, a fixed aperture of $f / 8$ could be selected to provide sufficient depth of field for the whole site without inducing evident diffraction softening. Since the amount of available illumination was too small to avoid hand-shake induced motion blur, the camera was mounted on a tripod and exposures were taken using a wireless remote shutter release. In addition, the mirror-lockup function was enabled to avoid vibrations that originate from the mirror slap (Verhoeven, 2016). After exhaustively covering the two building complexes with both large- and small-scale imagery from the ground, the camera was taken aloft by mounting it onto a $3 \mathrm{~m}$ extendable monopod (B.I.G. Monopod XXL). This approach enabled the acquisition of photographs at favourable angles of the upper parts of the building structures, while various inaccessible rooms could also be documented. For these elevated image series, the standard camera sensitivity of ISO 200 was raised to ISO 800 to counteract motion blur.

Additional outdoor laser scans were made in the neighborhood of the Akrotiri excavation, covering Mesa Vouno (Fig. 4), Kokkino Vouno and parts of Potamos valley. Using this data the geophysical datasets as well as the high-resolution TLS and IBM datasets from the excavation site itself could be referenced within an overall topographical model of the surrounding landscape. Additionally, the documentation of the recent topography is crucial for accurate postprocessing and visualisation of the geophysical data from a technical perspective and has to be taken in account when correcting GPR data topographically. Whenever an archaeological site is to be interpreted, the investigation of the archaeological landscape and its reconstruction are of highest interest. The landscape has changed dramatically since the Minoan eruption, presenting layers of up to $60 \mathrm{~m}$ of different pumice, tephra and volcanic bombs. Over the millennia surfaces have been transformed by wind and water, creating deep ravines and causing erosion and accumulation of material. Due to this significant erosion, the top of Kokkino Vouno is no longer covered by pumice, and prehis- toric graves have been uncovered in the Potamos valley. Considerable recent surface transformation has also been caused by the excavation and the setup of the needed infrastructure. The dump of the excavation was deposited into the Potamos valley, forming a steep slope facing south-east and a large quantity of pumice was removed to build a parking lot for visitors to the excavation site. All of these aspects need to be taken into account in order to reconstruct the topography of the pre-eruption landscape, as well as during interpretation and correction of the geophysical datasets.

During the campaigns of 2013 and 2014, a Riegl VZ-400 laser scanner was used to collect a total of 114 outdoor scan positions for the documentation of the recent topography of the site. For every station inclination, exterior orientation and location were recorded using onboard inclination sensors, compass and a GNSS receiver. The distances between the positions were within an average range of some 10 metres up to a maximum of 250 metres depending on the local topography and demanded resolution. According to the distance to be covered, the angular resolving power was set to 40 or 60 mdeg respectively. 29 of these positions were geo-referenced using cylindrical retro targets of $5 \mathrm{~cm}$ diameter. These targets were registered through an accompanying geodetic survey. In addition to the TLS survey a test kite aerial photography survey was carried out to cover the top of Kokkino Vouno. Within four days of fieldwork an overall area of about $1500 \mathrm{~m}$ $\times 800 \mathrm{~m}$, separated by three ravines and two mountain ridges, was documented at an average point density of approx. 50 to $150 \mathrm{pts} / \mathrm{m}^{2}$.

In February 2014, non-invasive GPR measurements using a 500 MHz Sensors \& Software pulseEkko Pro system with $25 \mathrm{~cm}$ profile spacing and earth resistance tomography (ERT) were conducted in the vicinity of the excavated site in search of subsurface archaeological remains. In Potamos valley ERT measurements were used in the vicinity of a known grave to attempt to locate cavities that could contain prehistoric graves. On Kokkino Vouno 


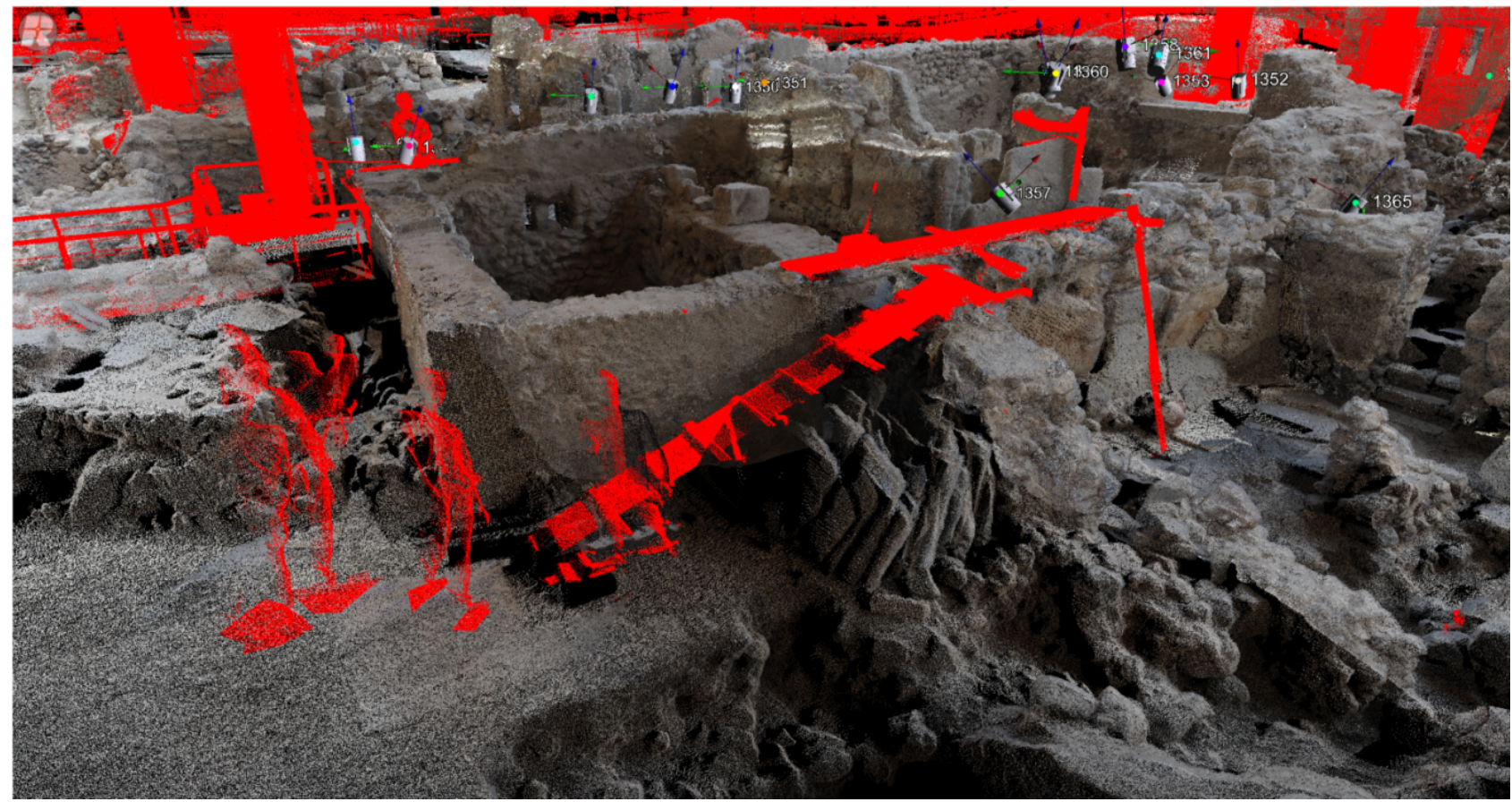

Figure 7: Laser scanning point cloud with Room 2 of Complex Beta in the centre and the modern structures separated (red). A virtually removed modern wooden ramp used by the architects studying the building can be seen in foreground.

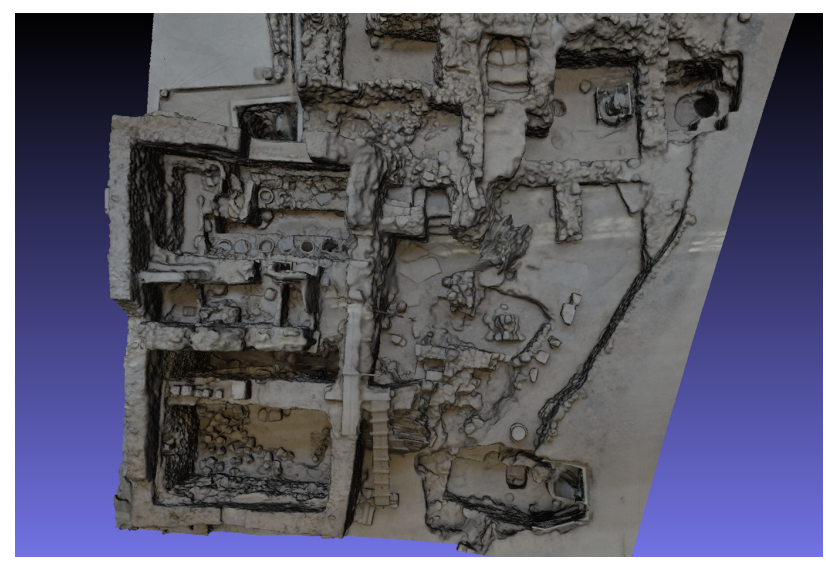

Figure 8: Image-based 3D model of Complex Beta.

GPR and ERT were used in an area where Spyridon Marinatos had in 1968 excavated a test trench, uncovering remains of walls and fragments of painted plaster. Here, fragments of variously coloured painted plaster can still be found on the ground surface, indicating remains of a more exclusive prehistoric building.

\subsection{Data processing}

2.2.1 TLS data: All acquired point clouds/scan-positions were registered and geo-referenced in RiSolve software with a targetbased approach using reflectors and tie points. In case of the outdoor scans all scan positions recorded without reflectors were aligned according to the workflow provided by the Riegl software package RiSolve. The registration of all scans was refined with Multi Station Adjustment (MSA), using an iterative closest point algorithm. The large number of indoor measurements acquired (Fig. 6) rendered the merging of the entire dataset for processing in one project impracticable on the computers available. Therefore, scans were processed together by day in separate projects. Different filters were applied in order to separate
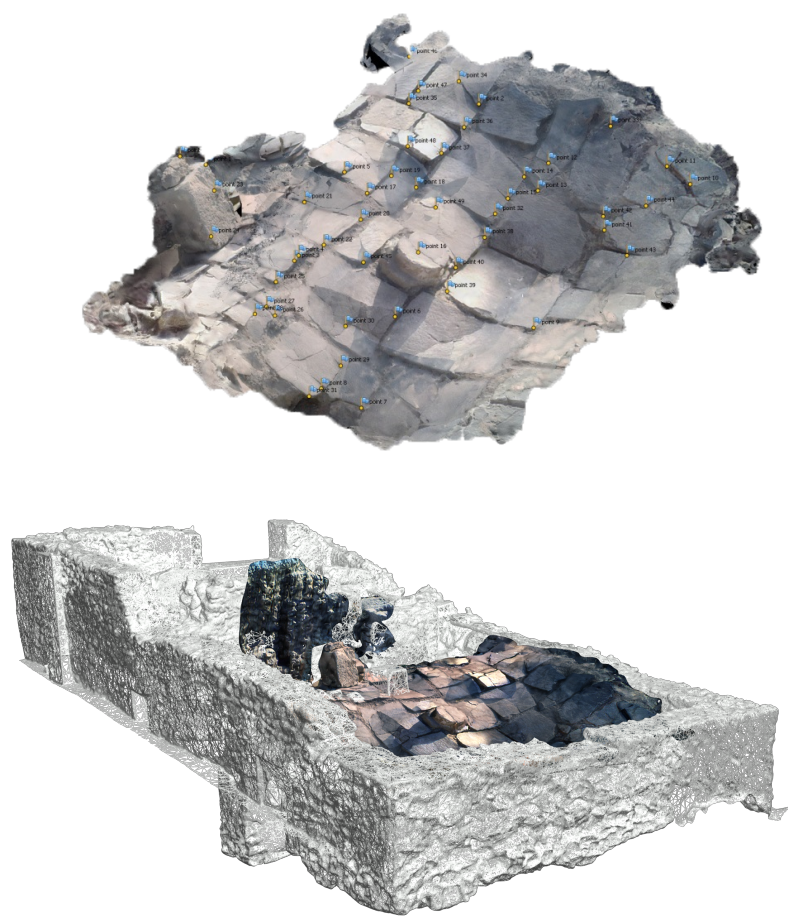

Figure 9: Top: 3D model of the excavated floor surface of Room 2 in Complex Beta generated through image-based modelling from photos taken in 1969, with the used tie points marked. This surface had been removed during the excavation process. Bottom: The reconstructed floor surface placed inside the 3D model of Room 2 of Complex Beta.

unwanted objects (roofing and pillars, supporting systems, visitor barriers and guiding systems, people) from prehistoric structures. A semi-automatic approach was applied, using predefined vegetation filters, custom morphological filters as well as manual 


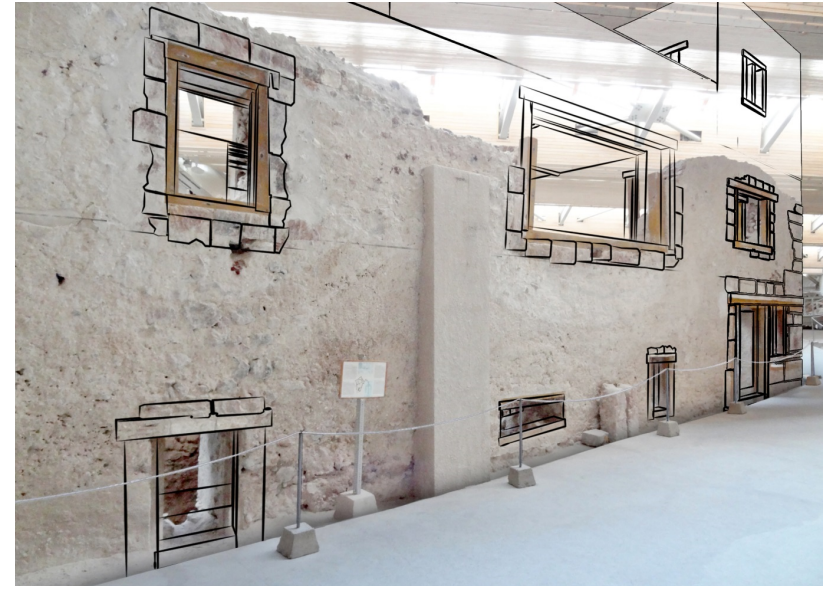

Figure 10: 3D virtual architectural suggestion superimposed onto a present day view of the Westhouse at Akrotiri's Triangle square. Such an augmented visualisation could help visitors to better understand and experience the former splendor of this town.

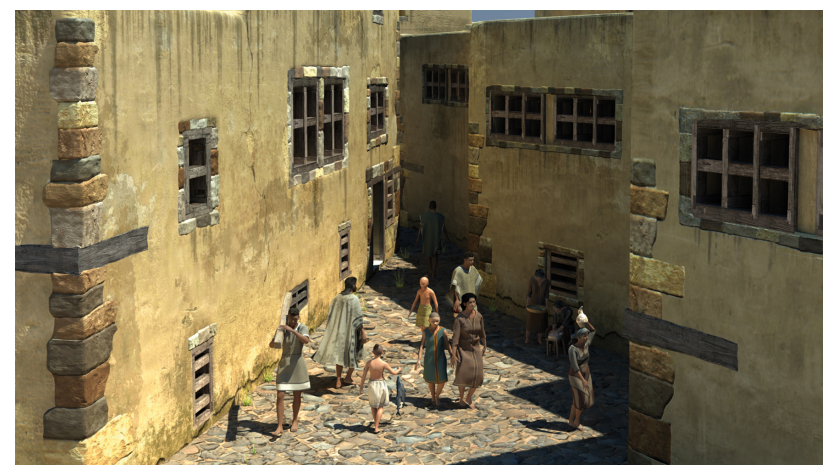

Figure 11: Virtually reconstructed 3D artist impression of Triangle square with the Westhouse to the left. The human figures were requested by National Geographic for a popular magazine publication.

point removal. Morphological classification was carried out using the CANUPO plugin for CloudCompare (Brodu and Lague 2012), which facilitates the classification of point clouds according to the geometry of the feature. A completely automated separation procedure was still not applicable due to the morphological similarity of structures (e.g. recent and prehistoric walls). As only two classes could be defined in each filter iteration and more were required, a combination of a custom vegetation filter in $R i$ Solve and manual filtering proved to be the least time consuming approach. The resulting, coloured point cloud, containing only prehistoric architecture, consisted of 1.9 billion points. The separation between the remaining coloured point cloud model and the cleaned structures is shown in Fig. 7.

2.2.2 Image-based modelling: After tagging all NEF files (Nikon Electronic Format, Nikon's proprietary RAW format) with the correct metadata, they were 'developed' into 16-bit TIFFs using Adobe Lightroom 5. During conversion, the global and local contrast of all image files was slightly enhanced and an Adobe RGB (1998) colour profile embedded. These files were corrected for vignetting but not for lens distortion, since the latter is taken care of in the IBM chain that was used to extract 3D geometry from them. Owing to the recent popularity of (semi-) automated image orientation techniques such as Structure from Motion (SfM) complemented by dense image-matching algorithms

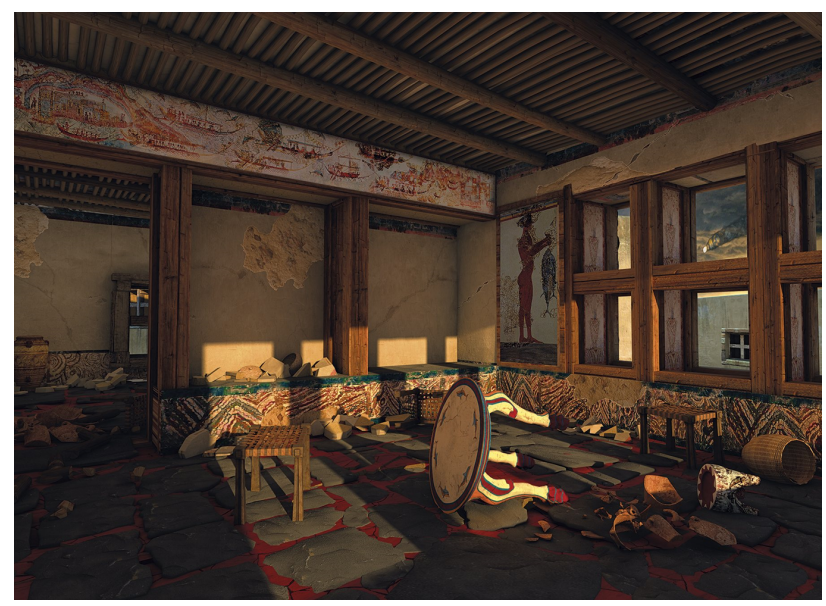

Figure 12: Atmospheric virtual reconstruction and artist impression of Room 5 of Westhouse at Akrotiri. The miniature Flotilla fresco can be see as well as one of the two fishing boy frescoes found in this room. Not all objects depicted in this image have been found inside this room.

embedded in Multi-View Stereo (MVS) approaches, IBM approaches have become commonplace in cultural heritage documentation. Although several SfM-MVS-based packages enable a (semi-)automated IBM processing pipeline, all image-based 3D model orthophotographs were computed using Agisoft's PhotoScan Professional Edition. In order to geo-reference the IBM results in the same coordinate reference system of the laser scanning data, the TLS targets were used. Given that they can function as satisfyingly accurate ground control, these targets were also used as constraints in the SfM bundle adjustment to correct for errors in the recovered camera orientations and avoid instability of the bundle solution.

IBM was used as well to attempt the reconstruction of one of the first archaeological excavations undertaken in the vicinity of Akrotiri. Using 22 digitized historical photographs taken in 1899 of Robert Zahn's excavation in Potamos valley some $500 \mathrm{~m}$ to the north-east of the Akrotiri site, the historical excavated area has been modelled in 3D. All the details usable for relocating the exact spot of Zahn's excavation were gathered, leading to a field in the Potamos valley where traces of the excavation are still detectable (Fig. 13). In a final step the scaled model of the 1899 excavation was located in reference to the new data acquired with TLS. Using this information, the excavation could be relocated to within 1-2 meters of its original position.

In addition, IBM with archived imagery was also executed to digitally model a part of the central excavation area of Akrotiri itself. Twelve photos taken during the excavation of Room B2 in complex Beta (then called Brounou 2) in 1967-69 have been used to generate a 3D model of the upper floor prior to its removal (Fig. 9). Given the highly non-uniform geometrical deformations of these images (resulting from the camera optics and complemented by possible film deformations as well as serious geometric errors that are introduced at the scanning stage), a dense set of manually indicated tie points - whose coordinates were extracted from the TLS point cloud - was used to force PhotoScan into computing an interior and exterior orientation for every image. Albeit highly inaccurate, these orientations proved sufficient to approximate this past surface with the subsequent dense image matching while also co-registering it with the TLS data. In this way the position of the removed stone slabs was created in a digital framework and represents the basis for further architectural analysis. relocated to their original position during excavation in 
a digital framework and now represent the basis for further architectural analysis. For the further virtual reconstruction of the ancient settlement, the geo-referenced IBM surface model has been merged with the model of the still standing laser scanned architecture to supplement the digital documentation. In doing so, it is possible to recreate and re-document the excavation process that, per se, is destructive.

2.2.3 Virtual reconstruction: Complementary to the 3D laser scanning of the site, it was also possible to draw some CAD models based upon the existing architectural floor plans published by site architect Clairy Palyvou (2005). These models provide a functional and useful source that has also been combined with the resulting point cloud in order to generate a more detailed digital model of the site. In this way it was possible to focus not only on the still standing remains, but also on other features such as architectural elements, everyday objects and furniture.

One of the main challenges within this part of the project was and still is - trying to include human figures into the $3 \mathrm{D}$ scenario. Being aware of the risks that this presents, it is crucial to consider that archaeological depictions of the past - no matter by classic drawings or using novel technologies - with no human presence are biased and incomplete images that will provide an incomplete representation of the past to the public as well as to the scientific community.

Another aspect that must be considered within these lines is the fact that due to the inherent attributes of virtual archaeology, the $3 \mathrm{D}$ visualisation presented is only one among many other possibilities. The cost efficient and interchangeable virtual reconstruction of architecture permits for the development of various different hypothesis, which can and should be discussed between the specialists of the site or topic.

2.2.4 Geophysical prospection data collected in case of both GPR and ERT measurements along parallel survey lines with $25 \mathrm{~cm}$ cross-line spacing, have been processed into 3D data volumes. GPR depth-slices and apparent resistivity distribution maps have been generated, showing the measured reflections as well apparent resistivity values at certain depth levels below the surface obtained through data inversion.

\section{RESULTS}

The TLS and IBM surveys resulted in an almost complete point cloud model of the excavated site of Akrotiri (with exception of a part of Complex Delta and one inaccessible room in Westhouse), as well as of a substantial part of the surrounding environment. This model serves as a "digital backup copy" of the site's real geometry in case of any further damage happening to the excavated structures. The acquired raw data have been deposited with the site archaeologists as well as with the Greek Ephorate of Antiquities of the Cyclades, and are also archived on servers of the University of Vienna.

After combining the laser scanning data with all the polymeshes generated by the various image-based modelling approaches and the existing architectural floor plans, several possible architectural interior scenes (Fig. 10) and complete virtual architecture reconstructions were generated (Fig. 12). The data are ideally suited for architectural as well as archaeological analysis of the site and the documented structures. Architects or archaeologists are now able to digitally extract relevant architectural information, such as wall thicknesses, angles and distances within the digital 3D model at the comfort of their desk - a task for which

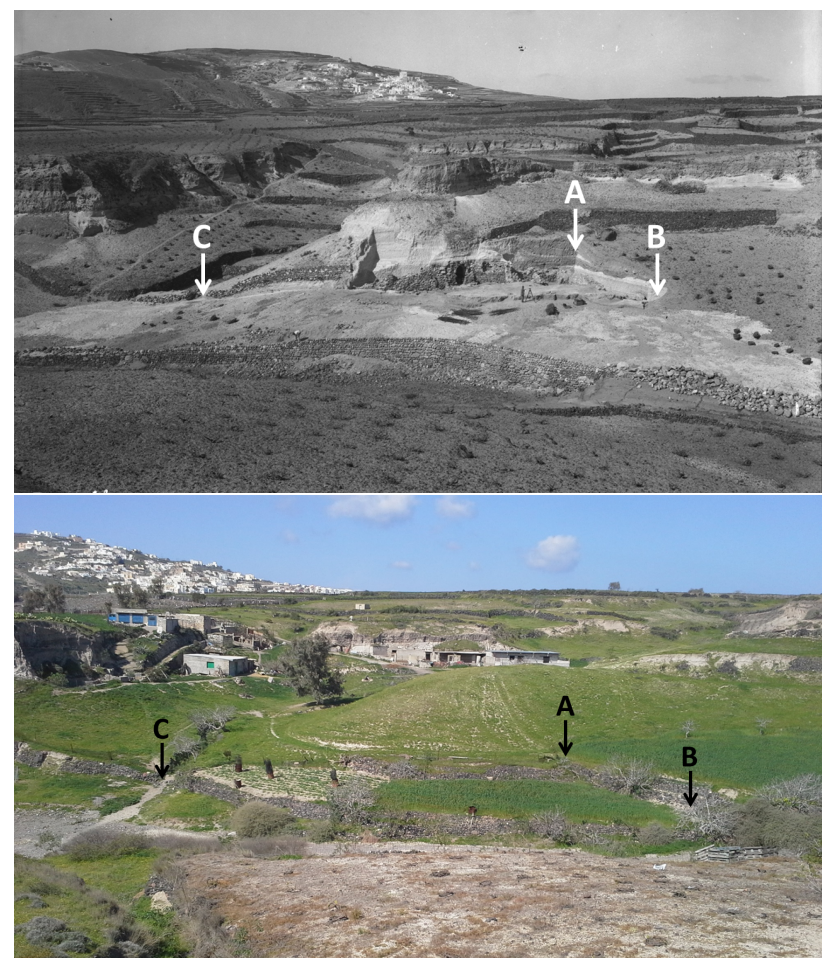

Figure 13: Top: Robert Zahn's excavation in 1899. Bottom: Zahn's excavation site is today a potato field, the steep slopes of the hill have eroded. Corresponding locations are marked.

until now tracing paper and a pencil on a wooden drawing board have been used in combination with a yard stick.

As shown here, it is possible to even reconstruct already removed surfaces, such as the 1969 excavated floor of Room 2 in Complex Beta, using historical photographs that have not been taken with this specific purpose in mind. By accessing the entire collection of historical photographs available, it should be possible to virtually reconstruct many further archaeological and architectural surfaces that have been removed during the excavation process.

Likewise, it would be possible to virtually place the fascinating frescoes found within Akrotiri back at their original position using the digital model. These have been restored and are currently kept in a largely inaccessible fresco archive. With the help of virtual and augmented reality applications it is now possible to provide the visitors of Akrotiri with a new fascinating experience of this unique archaeological site, visualising the splendour of this affluent town and the wealth of its Bronze Age inhabitants. Using augmented reality glasses or telescopes mounted on the railing of the pathways around the site, it would be possible to provide visitors to the Akrotiri excavation with a glimpse of the world depicted in the amazing frescoes. Similarly, it would be possible to virtually visualise different architectural reconstruction suggestions of those parts of the buildings and site that have been destroyed. Furthermore, the collected data and generated 3D models permit physical simulations of the architecture, the comprised contents, and the deformation processes that occurred due to seismic shocks and the weight and pressure of the pumice and ash cover deposited by the catastrophic volcanic eruption.

A detailed virtual 3D model of the Westhouse and Triangle square has been generated based on architectural plan drawings as well as the 3D models derived from TLS and IBM. This model can be accessed and navigated in virtual reality in order to explore 

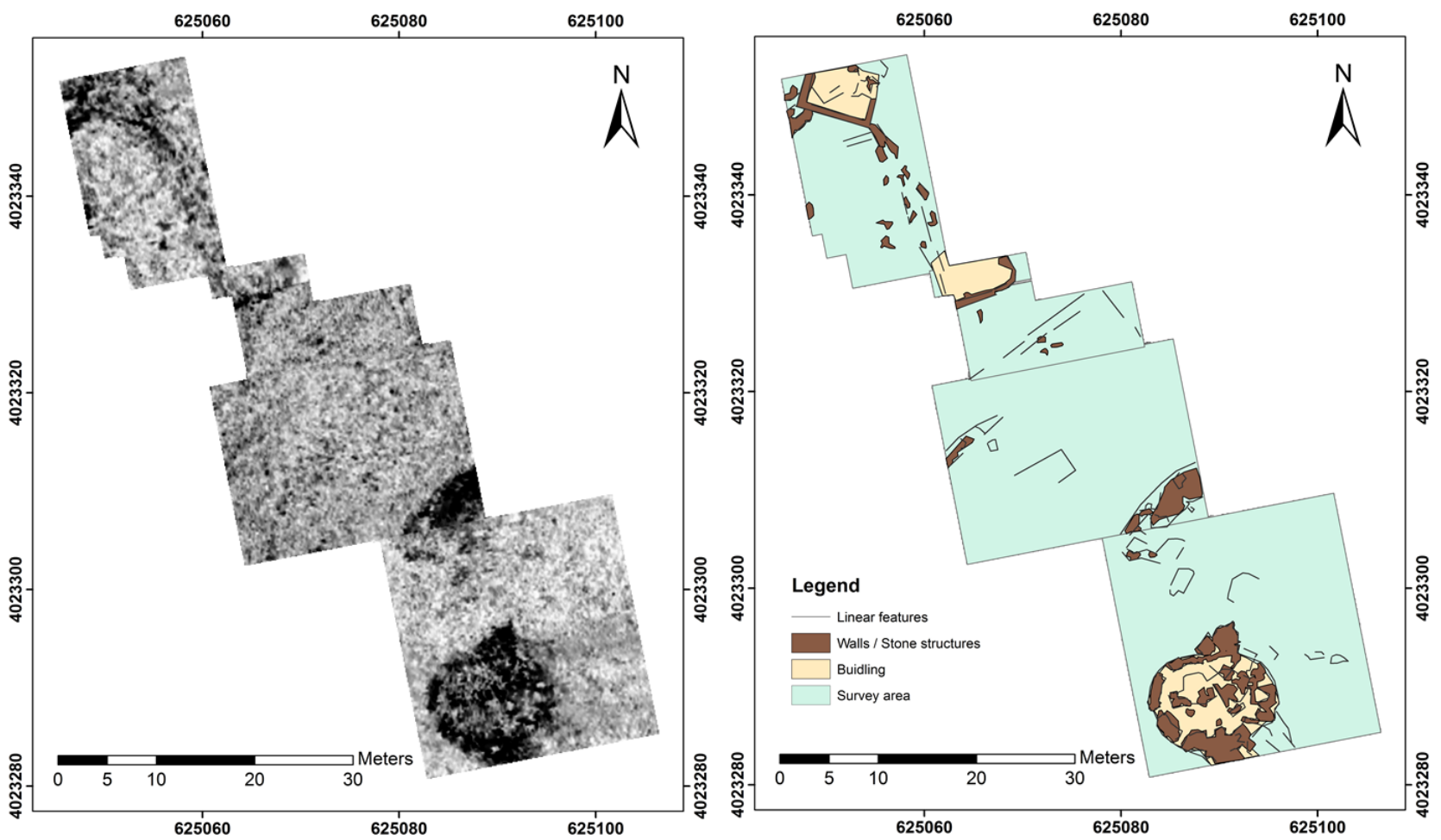

Figure 14: Results of ground-penetrating radar measurements on top of Kokkino Vouno. Left: A GRP depth-slice showing in dark strongly reflecting stone structures buried in the subsurface. In the northernmost part the remains of a rectangular building can be seen; in the middle part further wall structures are visible, close to the area where Marinatos had found badly preserved remains of prehistoric walls. The large circular structure in the southern part could be due to the remains of a trashing ground (not necessarily prehistoric), or present the remains of an ancient watch tower. Right: Interpretation of the GPR data. Coordinate system: GGRS87.

the building as it well may have looked like, providing unique insights into a lost world. The human figures depicted in the virtual reconstruction scene of Triangle square shown in Figure 11 had been requested by the editor of the National Geographic magazine, in which the project has been featured. While such popular visualisations unfortunately are still controversial amongst traditional members of the scientific community, the figures provide a scale and may be suited to appeal to younger audiences that otherwise would be difficult to reach.

GPR test measurements have resulted in the discovery of architectural remains on top of Kokkino Vouno (Fig. 14), that, due to surface finds of coloured wall plaster, without doubt can be dated to the Bronze Age. Following the hypothesis that the so-called arrival town depicted in the Flotilla miniature fresco (Fig. 15) from Westhouse at Akrotiri is a representation of the Akrotiri settlement, the GPR-mapped architectural remains may well correspond to buildings shown in the Fresco on a hill to the left of the Arrival town, likely rendering this fresco one of the first known naturalistic landscape depictions.

\section{CONCLUSIONS}

The outstanding excavated Bronze Age archaeological remains at the site of Akrotiri on the Greek island of Thera/Santorini are endangered by seismic activity, accidents and decay. A digital documentation using terrestrial laser scanning and image-based modelling was conducted to record and digitally safeguard the standing architecture. In parallel, ground-penetrating radar test measurements were conducted in order to detect and map still buried architectural remains. Using historical photographs, it was possible to locate and partly 3D construct the 1899 excavation of Robert Zahn in the nearby Potamos valley. Image-based modelling with archival imagery was also used to virtually generate previously removed surfaces in Akrotiri's Complex Beta.

This multi-source digital documentation project with a multisensory approach has been more than a mere scanning project - it has been a comprehensive 3D application that resulted in a virtual version of the endangered archaeological site of Akrotiri. This 3D digital model and data, comprising temporal aspects of the excavation process, has a great potential that can be used for detailed archaeological and architectural analysis, for the generation of scaled models, for enhanced visitor experience using existing virtual and augmented reality applications, while also serving as a highly accurate digital version of this outstanding cultural heritage site. The geophysical prospection test survey has successfully revealed still buried archaeology and supports future noninvasive exploration and investigation of this important site using these methods.

\section{ACKNOWLEDGEMENTS}

Funding: This work was supported by the National Geographic Society Conservation Trust [grant C219-12], the Ludwig Boltzmann Institute for Archaeological Prospection and Virtual Archaeology, and the University of Vienna.

Riegl Laser Measurement Systems supported the project with the loan of a VZ-400 laser scanner, advice and online support. The Central Institute for Meteorology and Geodynamics provided GPR equipment. MALÅ Geosience $\mathrm{AB}$ provided a GX $80 \mathrm{MHz}$ prototype antenna system for testing. 


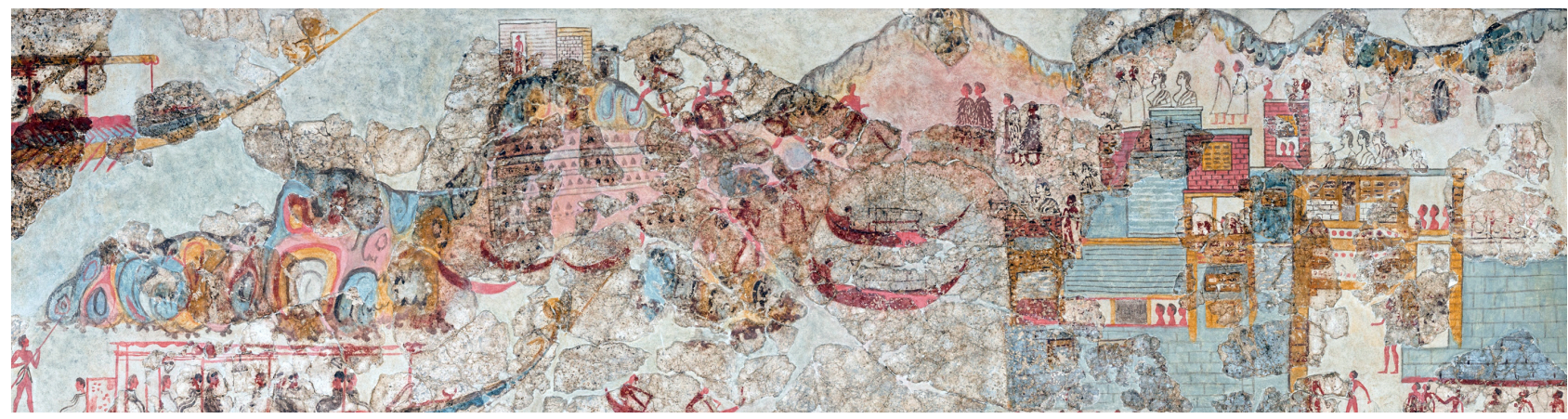

Figure 15: The miniature Flotilla fresco had been found in Westhouse room 5. It depicts a so-called "departure town" in its left part and and the so-called "arrival town" in its right part (shown here). Between the two towns 12 ships and boats have been painted. Behind and to the left of the "arrival town" several hills are shown. A group of four men dressed in fur coats are walking towards the second hilltop left of the "arrival town", on which three buildings can be seen. Following the hypothesis that this hill corresponds the Kokkino Vouno, then the GPR measurements conducted there are likely to have mapped the prehistoric remains of the buildings shown in this fresco.

Prof. Gregory Tsokas, Panagiotis Tsourlos and George Vargemezis from Aristotle University in Thessaloniki contributed to the archaeological prospection project with earth resistance tomography measurements in 2014. Site director Prof. Christos Doumas and Prof. Andreas Vlachopoulos supported the project and kindly provided access to the site.

Participants of the 2013 fieldwork campaign were Immo Trinks, Geert Verhoeven, Matthias Kucera, Christopher Sevara, Erich Nau, Christos Doumas, Andreas Vlachopoulos, Konstantinos Athanasiou, Christos Doulgeroglou and Ioannis Bitis.

Participants of the 2014 fieldwork campaign were Immo Trinks, Matthias Kucera, Klaus Löcker, Geert Verhoeven, Andreas Vlachopoulos, Gregory Tsokas, George Vargemezis, Panagiotis Tsourlos, Eamonn Baldwin, Joris Coolen, Ulrike Fornwagner, Manuel Gabler, Martin Gamon, Viktor Jansa, Jakob Kainz, Michal Rus, Petra Schneidhofer, Tomas Tencer, Katalin Tolnai, Willem Vletter and Mario Wallner.

\section{REFERENCES}

Brodu, N., Lague, D., 2012. 3D Terrestrial LiDAR data classification of complex natural scenes using a multi-scale dimensionality criterion : applications in geomorphology, ISPRS Journal of Photogrammetry and Remote Sensing, 68, p. 121-134.

Castleden, R. 1998. Atlantis Destroyed. Routledge,Taylor \& Francis Group, London and New York.

Doumas, C., 1983. Thera: Pompeii of the Ancient Aegean: Excavations at Akrotiri, 1967-79. Thames and Hudson, London.

Fouqué, F., 1879. Santorin et ses éruptions. Masson, Paris.
Friedrich, W., 2009. Santorini - Volcano - Natural History . Mythology. Aarhus University Press.

Heinemeier, J., Friedrich, W.L., Kromer, B., Bronk Ramsey, C., 2009. The Minoan eruption of Santorini radiocarbon dated by an olive tree buried by the eruption. In D.A. Warburton, editor, Time's Up! Dating the Minoan eruption of Santorini. Acts of the Minoan Eruption Chronology Workshop, Sandbjerg November 2007, volume 10 of Monographs of the Danish Institute at Athens. The Danish Institute at Athens, Athens.

Marinatos, S., 1999a. Excavations at Thera I-III. 1967-69 Seasons. No. 178. The Archaeological Society At Athens, Athens.

Marinatos, S., 1999b. Excavations at Thera IV-V. 1970-1971 Seasons. No. 179. The Archaeological Society At Athens, Athens.

Marinatos, S., 1999c. Excavations at Thera VI-VII. 1972-1973 Seasons. No. 180. The Archaeological Society At Athens, Athens.

Mavor, J.W., 1973. Voyage to Atlantis. Fontana, London.

Palyvou, C., 2005. Akrotiri Thera: An Architecture of Affluence 3,500 Years Old. INSTAP Academic Press.

Tzachili, I., 2005. Excavations on Thera and Therasia in the 19th Century: A Chronicle. Journal of Mediterranean Archaeology, 18(2), pp. 231257.

Verhoeven, G., 2016. Basics of photography for cultural heritage imaging, in: Stylianidis, E., Remondino, F. (Eds.), 3D Recording, Documentation and Management of Cultural Heritage. Whittles Publishing, Caithness, pp. 127251. 